\title{
УДК 14
}

\author{
С. А. ЮРИКОВА ${ }^{1 *}$ \\ 1*Орловский государственный институт искусств и культуры (г. Орёл, Россия)
}

\section{ПЕРСПЕКТИВЫ ЧЕЛОВЕЧЕСТВА В УСЛОВИЯХ ТЕХНОГЕННОЙ ЦИВИЛИЗАЦИИ}

Цель. Очертить круг проблем, характерных для современной техногенной цивилизации, отразить ее противоречивый характер и перспективы человечества в ее условиях. Бурное развитие научно-технического прогресса постепенно, начиная с конца 60-х годов XX столетия, стало приводить к осознанию проблем, которые он порождает, к пониманию того, что без серьезного, пристального контроля за его развитием и необходимого философского анализа этих проблем, существует опасность формирования в будущем «постчеловеческого» мира. Методология. Автор использовал системный и аналитический методы исследования. Научная новизна. Осуществлен комплексный подход к обозначению и анализу проблем, с которыми столкнулось современное человечество в условиях техногенной цивилизации. Практическое значение работы состоит, прежде всего, в том, что в ней акцентируется внимание на необходимости скорейшего серьезного, продуманного внимания к этим проблемам, чтобы избежать в будущем опасностей, которые они таят для человечества. Кроме того, материал, изложенный в статье, может использоваться в преподавании социально-гуманитарных дисциплин. Выводы можно свести к следующим основным положениям: научнотехнический прогресс является главным фактором развития современной техногенной цивилизации. Порождаемый им большой круг проблем требует понимания необходимости жесткого контроля за развитием техники. Спонтанное, непродуманное дальнейшее ее развитие и использование может постепенно привести к «постчеловеческому миру». Опасность осуществления такого сценария должна породить необходимость более пристального внимания, обсуждения и анализа уже существующих проблем и выработки мер, способных обеспечить выживание человечества в условиях современной техногенной цивилизации.

Ключевые слова: техника, наука, прогресс, человек, человечество, техногенная цивилизация.

\section{Актуальность}

Научно-технический прогресс стал главным фактором, определившим развитие человеческого общества в XX веке и обусловившим его своеобразие. Жизнь современного человечества уже немыслима без дальнейшего его развития. Необходимость же осмысления последствий была осознана не сразу. Примерно до 70-х годов XX века философские проблемы техники не обсуждались широко в обществе. Они волновали лишь сравнительно небольшой круг философов XX века. Речь идет прежде всего о таких мыслителях, как Ф. Дессауэр, Л. Мэмфорд, Х. Ортега-и-Гассет, М. Хайдеггер, О. Шпенглер, К. Ясперс и др. В России одним из родоначальников философии техники стал русский инженер П. К. Энгельмейер, написавший еще в начале $\mathrm{XX}$ века работы «Теория творчества» и «Философия техники». Проблемы развития техники были также в центре внимания Н. А Бердяева и др.

К концу 60-х годов в общественном созна- нии начинают обозначаться экологические проблемы, приходит понимание того, что на природу нельзя уже смотреть как на кладовую без дна, что увеличивающееся давление на природу со стороны социума может привести к серьезным последствиям. О том, насколько серьезны эти опасения, показали результаты исследований, проведенных учеными Римского клуба под руководством Д. Медоуза, которые были отражены в Докладе «Пределы роста». Публикация книги более чем на 35 языках под таким же названием вызвала сенсацию во всем мире. Главный вывод, содержащийся в книге, был далеко не утешительным - человечество движется навстречу глобальной катастрофе. Избежать ее, подчеркивали ученые, можно лишь в том случае, если будет уменьшено давление на природу, а для этого необходимо ограничение, регулирование роста производства, добычи и переработки природных ресурсов. Результаты исследований поставили под сомнение существовавшие представления о критерии социального прогресса, который усмат- 


\section{ФІЛОСОФІЯ НАУКИ І ТЕХНІКИ}

ривали в непрерывном наращивании производственных мощностей ради все большего производства материальных благ.

Осознание проблем, которые породила научно-техническая революция (загрязнение окружающей среды, истощение природных ресурсов, исчезновение видов животных и растений, угроза техногенных катастроф, ядерной войны и др.) привело, в свою очередь, к пониманию необходимости контроля за развитием техники, недопущением спонтанного непродуманного ее развития и использования.

\section{Цель}

Цель данной статьи - очертить круг проблем, характерных для современной техногенной цивилизации, отразить ее противоречивый характер и перспективы человечества в ее условиях.

\section{Методология}

Автор использовал системный и аналитический методы исследования.

Современное человечество, как справедливо подчеркивают современные ученые, вступило в этап своего развития, исторически сравнимый со становлением неолита, но по значимости и последствиям для человеческой жизни значительно его превышающим. Развитие научнотехнического прогресса обусловило техногенный характер современной цивилизации, привело к несоизмеримости деяний человека с caмим собой как природным существом. Стало возможным говорить о формировании «постчеловеческого» мира, т.е. мира, создаваемого человеком, но который будет существовать независимо от него и развиваться по своим законам. Осознание возможности осуществления такого сценария заставило современных ученых обратить пристальное внимание к проблеме техники, перспектив ее дальнейшего развития и последствий его для человека.

На протяжении почти всей истории люди мечтали о средствах, которые бы позволили облегчить труд человека, интенсифицировать его. Эти мечты, которые находили сначала свое воплощение в мифах (миф о Прометее, научившем людей техническим навыкам, миф о Дедале и его сыне Икаре, осуществлявших полет с помощью крыльев, миф о строительстве
Вавилонской башни и его неудаче), в сказках (вспомним, к примеру, ковер-самолет, летающую метлу Бабы-Яги, сапоги-скороходы и т. д.), в полной мере стали сбываться с начала XX века, когда техника активно стала входить в жизнь людей.

О том, как повлияет на жизнь людей развитие научно-технического прогресса, размышляли в то время преимущественно представители творческой интеллигенции - художники, поэты. Как отмечали футуристы, люди были просто опьянены достижениями технического прогресса. Жизнь мотора, подчеркивали они, теперь больше волнует художников, чем слезы и улыбка женщины. Однако в начале XX века высказывались и пессимистические прогнозы относительно последствий дальнейшего развития техники. Например, опасения высказывали представители абстракционизма, у истоков которого стоял В. Кандинский. Знаменитый «Черный квадрат» К. Малевича исследователи рассматривают как обобщенный образ индустриальной технологии, оперирующей стандартными узлами и деталями, как символ утраты духовного измерения.

Эти опасения оказались не напрасными. К концу XX века была создана техногенная цивилизация. Ее самой опасной и существенной чертой считают возможность утраты человеком власти над техническим прогрессом и его последствиями. Как справедливо однажды заметил Б. Рассел, наука и техника движутся сегодня вперед, словно танковая армада, лишившаяся водителей, - слепо, безрассудно и без определенной цели.

На сегодняшний день проблема принципиальной непредсказуемости дальнейшего развития научно-технического прогресса - это самая серьезная проблема, которая требует самого пристального к себе внимания не только ученых. Она должна быть в центре внимания правительства каждой страны и обсуждаться на высоком международном уровне.

Среди современных ученых нет единого мнения относительно последствий для человека развития научно-технического прогресса. Очевидные позитивные его последствия, выражающиеся в совершенствовании производства, облегчении труда людей, создании условий для более комфортабельной жизни, стали основой 


\section{ФІЛОСОФІЯ НАУКИ І ТЕХНІКИ}

для оптимистической оценки роли техники в жизни людей. Таких взглядов придерживаются представители технократического подхода, связывающие с дальнейшим развитием научнотехнического прогресса большие надежды на будущее. И если для индустриальной эпохи характерен был «миф машины» со свойственной ему верой в торжество технического прогресса, то в современную эпоху сторонники этого подхода, как отмечают современные исследователи, создали миф об информации, электрическом мозге, компьютерном прогнозировании, всепланетной экранной культуре [7, с. 304].

Представители другого, гуманитарного подхода высказывают серьезную озабоченность относительно его последствий в будущем и обосновывают необходимость более пристального философского анализа техносферы, без которого невозможно решение существующих и назревающих техногенных проблем [5]. Их опасения связаны с тем, что человек, постепенно уверовав во всемогущество техники, незаметно для себя, отойдет от ценностей гуманитарного характера, таких как добро и красота, толерантность, способность сочувствовать и сострадать ближнему, что может привести к дегуманизации общественных, межчеловеческих отношений.

Благодаря развитию научно-технического прогресса создано общество потребления, в котором человек в большинстве случаев оказывается вовлеченным в бесконечную погоню за всякий раз более совершенными товарами, соответствующими модным тенденциям, его имиджу и т.д. Постепенное окружение людей себя техникой, вещами приводит к изменению характера общения между ними. Как справедливо подчеркивал известный философ, социолог, культуролог Ж. Бодрийяр, что если в прежние времена человек жил в окружении других людей и общался с себе подобными, то в этом обществе изобилия человек окружает свою жизнь объектами потребления [2].

Техника помогла человеку освободиться от «объятий природы», от природной необходимости, взять под свой контроль многие природные процессы. Но сегодня стало совершенно очевидным, что человек оказался в зависимости от технической необходимости. Это выражает- ся в том, что у созданной человеком искусственной реальности появляется тенденция к онтологизации, саморазвитию, к появлению имманентных закономерностей и своих «интересов».

Появилась опасность развития производства для себя самого. Если до XX века техника была нейтральным средством деятельности человека, то теперь, прочно и глубоко внедрившись во все сферы жизни человеческого общества, она диктует человеку свои условия, задает ему цели. В связи с этим стало возможным говорить об «индустриальном эгоизме». Например, строительство электростанций нужно для выработки энергии, энергия, в свою очередь, нужна для производства стали, сталь нужна для производства цемента, цемент нужен для строительства электростанций. И так каждый цикл, отмечают современные исследователи, с приращением. Сегодня, например, говорят о феномене саморазвития транспортных коммуникаций. Развивающиеся и укрупняющиеся города требуют совершенствования и расширения транспортных сетей. Но эта последняя задача решается на основе уже имеющихся дорог. И город должен уже подстраиваться под существующие коммуникации, выискивая возможности перераспределения транспортных потоков, создания кольцевания, развязок, что требует зачастую освобождения определенных территорий, что может противоречить задачам сохранения исторической среды, чистоты, тишины.

Другая проблема связана с тем, что за развитием научно-технического прогресса стоят интересы конкретных людей. Созданное одним, совершенствуется и продолжается другими, достигая постепенно огромных масштабов, заставая которые и находясь перед дилеммой дальнейшего развития, сопряженного с вредом для себя, или отказа от него, люди часто руководствуются принципом неотвратимости: «все равно не остановишь». Вынужденные быть в курсе технологического прогресса, заинтересованные в том, чтобы не отстать от других, создать условия для своей безопасности, страны, на уровне правительств, принимают решения, способствующие дальнейшему техническому прогрессу. Как верно замечается современными исследователями, необходимость прогресса 
обосновывается самим прогрессом. Так, известно, что несмотря на неверие в эффективность американской стратегической оборонной инициативы (СОИ), все прекрасно понимают, что ее осуществление приведет к утрате контроля со стороны человечества за решениями вопросов о войне и мире. Здесь уместно вспомнить слова великого советского ученого М. Бахтина: «Страшно все техническое ..., отданное закону своего развития, оно может время от времени врываться в это единственное единство жизни как безответственно страшная и разрушительная сила» [1].

Современное состояние науки и техники позволяет реализовывать самые смелые идеи и проекты, которые, с одной стороны, позволяют решать сложнейшие задачи, а с другой стороны, порождают еще более серьезные проблемы и последствия. Так, успехи в области генной инженерии и биотехнологий помогают в поиске новых возможностей в решении медицинских, производственных, сельскохозяйственных проблем. Но в то же самое время, как считают специалисты, обеспечивая возможность вмешательства в наследственную природу, создают угрозу человеческой индивидуальности, могут привести, например, к расшатыванию природного иммунитета человека.

Совершенствуя созданный благодаря достижениям науки и техники искусственный мир, человек попадает часто в замкнутый круг. Так обстоит дело, например, с решением некоторых экологических проблем, в частности с очищением воды. Решение этой задачи требует сначала нахождения в лабораториях ученых веществ, с помощью которых можно было бы улучшить состояние воды. Затем необходимо создать предприятия по их выпуску, деятельность которых также сопровождается выбросом в атмосферу вредных веществ, стоком использованной, грязной воды. К тому же, для того, чтобы обезвредить вредные выбросы, необходимо создать более мощное по воздействию вещество, процесс производства которого будет более сложным. Далее встает задача обезвреживания последствий создания этих мощных очистителей и т.д.

Созданный человеком техномир, заставляет его приспосабливаться к законам функционирования технических устройств, мириться с экологическими последствиями. Здесь уместно будет вспомнить М. Хайдеггера, который, анализируя результаты технического прогресса, высказывает пессимистические идеи. Развитие техники привело к появлению «технического мира», который является показателем мощи и универсальности техники. Но вместе с тем этот мир начинает подчинять своему диктату все пространство бытия. М. Хайдеггер приводит пример с рекой Рейн, на которой построена электростанция, которая не встроена в реку так органично, как старый деревянный мост, связывающий два берега. Теперь река скорее встроена в электростанцию, став поставщиком гидравлического напора. А как река Рейн остается интересен разве что для осмотра экскурсионной компанией.

Он одним из первых пророчески высказал идею о непредсказуемости в будущем результатов развития техники. Это объясняется тем, что развитие техники необходимо связано с непрерывной заданностью мышления, поведения, сознания людей. Через сущность техники человек говорит с бытием, слышит его зов. Но главная задача человека - верно угадать импульс техники, так как техника может провоцировать его на ложное самораскрытие. Самое опасное последствие развития технического прогресса он видит в том, что человек может быть выдан технике, «затребован» ею, что не техника будет подчиняться ему, а он окажется во власти диктата техники [8].

Благодаря развитию научно-технического знания происходит постоянное совершенствование технических устройств, увеличивается их выпуск, что усиливает давление на окружающую природную среду. Например, с каждым годом увеличивающийся поток личного транспорта создает не только проблемы, связанные с пробками на дорогах, но очень сильно загрязняет воздух в городах, что негативно сказывается на здоровье людей. Благодаря технике человек, с одной стороны, значительно облегчает себе жизнь, а с другой стороны, вынужден расплачиваться за это другими проблемами: за жилищный комфорт - разобщенностью людей, за техническое совершенствование производства - безработицей, проблемой досуга, его организации и т.д.

Чем более мощной по степени своего воз- 


\section{ФІЛОСОФІЯ НАУКИ І ТЕХНІКИ}

действия становится техносфера, тем более строгие требования предъявляются к профессиональным качествам человека. Современный специалист должен обладать глубокими знаниями, от него требуется четкое выполнение технологических стандартов. Появление мощных технологий изменило понятие профессионализма. Многие современные проблемы, как показывает практика порождены прежде всего некомпетентностью и дилетантством. Глобальный характер технического действа, отмечают сегодня, не позволяет двигаться эмпирическим путем - методом проб и ошибок, так как последствия неверных шагов, непродуманных решений будут необратимыми.

Высокий профессиональный уровень подготовки, компетентность является гарантом надежности, стабильности и перспективности технических систем. Компетентность предполагает широкий информационный кругозор, аналитический склад ума, знание общих естественно-научных законов и свойств природных материалов. Особые, повышенные требования к современному специалисту обусловлены сложностью, порою повышенною, технических систем. Сложность таких технических объектов, например, как атомные электростанции и др., превосходит контролирующие возможности человека.

Созданный людьми техномир, можно сказать, мстит людям за их некомпетентность, за незнание его законов и пренебрежение к ним. В связи с этим подвергается сомнению положение о том, что человек является субъектом сотворенного им мира. Здесь уместно привести печальную шутку польского философа Ст. Ежи Леца: наука и техника так совершенствуются, что человек скоро сможет обойтись без самого себя.

Становление техногенной цивилизации привело к девальвации духовных ценностей, к формированию технократического типа личности с соответствующим технократическим стилем мышления, в основе которого вера во всемогущество рациональных методов, и соответствующей системой ценностей. В этой системе высшими ценностями становятся деньги, прибыль могущество, власть. Здесь истинные нравственные ценности утрачивают свое высокое значение и приобретают новое, соответст- вующее технократическому стилю мышления. Например, добро начинает отождествляться с выгодой, счастье - с обладанием.

Развитие научно-технического прогресса в XX веке привело, как подчеркивают исследователи, к превышению сферы жизни людей сферой их деятельности, к преодолению сначала чувственных, а теперь и мысленных ее границ. Современный человек живет в качественно ином мире, который ученые стали называть постчеловеческим уже в 80-х годах прошлого века. «Мир человека перестал быть равным его дому. Природное бытие людей (узкий диапазон температур, давления, состава воздуха, в котором мы можем жить) вступает в противоречие с их деятельностной реальностью и при случайном неопосредованном контакте с ней (радиацией, излучением, скоростью) терпит поражение. Из средства жизни наше окружение превращается в средство труда. В современном мире все меньше мест, все меньше времени, где и когда человек действует как целостное телесно-духовное существо. Это глубинная причина проблем экологии и кризиса гуманизма: живое за пределами жизни! Таков первичный, базовый смысл, определяющий постчеловеческое измерение мира» [4, с. 274]. В сложившейся ситуации, подчеркивает В. А. Кутырев, обнаружился как бы внутренний кризис могущества человека, обостривший проблемы экологии, гуманизма, общим знаменателем которых является становление «постчеловеческого» мира, мира, созданного человеком и обретающего независимость от своего творца.

Но пока еще речь идет о становлении «постчеловеческого» мира, у современного человека есть еще время подумать о последствиях своих решений и действий. В принципе, как справедливо замечал другой известный ученый В. П. Визгин, любое творение человека, выводящее его на контакт с бытием, ведет себя как мир, т.е. как автономное образование, наделенное бесконечностью значений, открытое для дальнейшего явления и бросающее своей «неисчерпаемостью» вызов человеку как своему творцу [3, с. 62].

Развитие научно-технического прогресса привело и к качественному изменению современного общества, которое стало информационным. Созданы системы искусственного ин- 
теллекта, благодаря которым появляются новые виды деятельности, в которых реальные чувства и человеческое мышление уже не являются для человека ориентиром. Компьютерноинформационная реальность становится для человека значимее вещно-объектной реальности. Осмысление сущности информационного общества, проблем и перспектив его развития также находится в центре внимания современных ученых.

Сложившаяся ситуация, когда человек, благодаря достижениям развития науки и техники, получил возможность выходить за пределы своего не только чувственного, но и мысленного мира, когда он оказывается «не один» в созданной им самим человеко-машинной цивилизации, а становится ее компонентом, фактором, заставляет задуматься над вопросами о месте человека в качественно новом для него мире, о границах отношения к нему как к фактору развития современной цивилизации, о том, чтобы «постчеловеческая» реальность не привела постепенно к существованию мира без человека.

Размышляя о состоянии и тенденциях дальнейшего развития современной техногенной цивилизации, многие ученые приходят к выводу, что перспектив у нее нет, что и свидетельствует о ее кризисе. При ответе на вопрос о возможности преодоления этого кризиса высказываются как пессимистические, так и оптимистические точки зрения.

\section{Научная новизна}

Осуществлен комплексный подход к обозначению и анализу проблем, с которыми столкнулось современное человечество в условиях техногенной цивилизации. Практическое значение работы состоит прежде всего в том, что в ней акцентируется внимание на необходимости скорейшего серьезного, продуманного внимания к этим проблемам, чтобы избежать в будущем опасностей, которые они таят для человечества. Кроме того, материал, изложенный в статье, может использоваться в преподавании социально-гуманитарных дисциплин.

\section{Выводы}

Согласно оптимистическим точкам зрения у современной техногенной цивилизации есть шанс выжить в том случае, если, во-первых, произойдет осознанное изменение приоритетов в шкале ценностей, отношения к природе и формирования экологической культуры. Это предполагает рассмотрение проблем развития техники в тесной связи с экологическими и нравственными проблемами. Иначе говоря, экологический и социокультурный смыслы техники должны существовать в единстве.

Во-вторых, техника должна приобрести человеческое измерение, т.е. критерием целесообразности всех технических изобретений должна быть прежде всего польза для человека, a затем уже технико-технологическая оптимальность и экономическая эффективность. Совершенствование оценок техники, как справедливо отмечают современные исследователи, связано со сложностью переориентации групповых интересов на общечеловеческие. В связи с этим обосновывается необходимость новой дисциплины - антропологии техники, которая бы, учитывая выше сказанное, нацеливала бы на создание глобальных программ, нейтрализующих негативные последствия технического прогресса [6].

Другим важнейшим условием преодоления кризиса считают революционные изменения инженерного мышления и действия, в развитии которого выделяют три этапа. На первом этапе главной задачей было - понять «онтологическую» природу принципов действия технических устройств, что происходило часто на интуитивном, практическом уровне. На втором этапе развития инженерии, который называют логико-гносеологическим, главной задачей стало - понять, какими методами и способами создаются и эксплуатируются технические объекты. На этом, подчеркивают сегодня ученые, и базируется современное инженерное образование. При этом главным критерием инженерного мышления и действия становится техническая эффективность. В этих условиях техника становится целью и главным содержанием деятельности человека. В результате, как сказал Б. Пастернак, «техники много, а духа нет».

Третий, возможный и необходимый, этап связывают с социокультурным осмыслением техники. Он предполагает человеческое измерение техники с осмыслением всегда последствий ее развития для человечества в целом, что, в свою очередь, предполагает высокий уровень 


\section{ФІЛОСОФІЯ НАУКИ І ТЕХНІКИ}

ответственности за изобретение и его использование. Такой подход должен привести к созданию глобальной системы «Техническое устройство - Человек - Окружающая среда», где все три компонента должны быть равноправными. Такой подход не допускает доминирования какого-либо компонента в этой системе и должен обеспечить гармоническое сосуществование их. При этом высшей ценностью в этой системе должен быть человек. Поэтому суть и смысл дальнейшего развития техники должны заключаться в выработке таких проектировочных стратегий и контролирующих систем, которые бы обеспечили человеческое выживание.

\section{СПИСОК ИСПОЛЬЗОВАННЫХ ИСТОЧНИКОВ}

1. Бахтин, М. М. К философии поступка / М. М. Бахтин // Философия и социология науки и техники. - М.,1985.

2. Бодрийар, Ж. Общество потребления / Ж. Бодрийар. - М., 2006.

3. Визгин, В. П. Культура-знание-наука / В. П. Визгин // Наука и культура. -М.,1984.

4. Кутырев, В. А. Проблема выживания человека в «постчеловеческом» мире. /В. А. Кутырев // Человек в системе наук. - М., 1989.

5. Попкова, Н. В. Философия техносферы /

Н. В. Попкова. - М., 2009.

6. Попкова, Н. В. Антропология техники. Проблемы, подходы, перспективы / Н. В. Попкова. M., 2011.

7. Савкина, А. В. Киберрелигия итехноязычество в современном обществе / А. В. Савкина // Философские опыты. - Вып. 2. Человек. Общество. История. - М., 2009.

8. Хайдеггер, М. Вопрос о технике / М. Хайдеггер // Время и бытие. - М.,1993.

\section{С. А. ЮРИКОВА ${ }^{1 *}$}

${ }^{1 *}$ Орловський державний інститут мистецтв і культури (м. Орел, Росія)

\section{ПЕРСПЕКТИВИ ЛЮДСТВА В УМОВАХ ТЕХНОГЕННОЇ ЦИВІЛІЗАЦІї}

Мета. Окреслити коло проблем, характерних для сучасної техногенної цивілізації, відобразити іiі суперечливий характер і перспективи людства в їі умовах. Бурхливий розвиток науково-технічного прогресу поступово, починаючи 3 кінця 60-х років XX століття, став приводити до усвідомлення проблем, які він породжує, до розуміння того, що без серйозного, пильного контролю за його розвитком і необхідного філософського аналізу цих проблем, існує небезпека формування в майбутньому «постлюдського» світу. Методологія. Автор використовує системний та аналітичний методи дослідження. Наукова новизна. Здійснено комплексній підхід до позначення та аналізу проблем, з якими зіштовхнулося сучасне людство в умовах техногенної цивілізації. Практичне значення роботи полягає, перш за все, у тому, що в ній акцентується увага на необхідності скорішої серйозної, продуманої уваги до цих проблем, щоб запобігти в майбутньому тих небезпек, які вони несуть людству. Крім того, матеріал, викладений у статті, може бути використано у викладанні соціально-гуманітарних дисциплін. Висновки можливо звести до наступних основних положень: науково-технічний прогрес $є$ головним фактором розвитку сучасної техногенної цивілізації. Велике коло проблем, що ним породжено, потребує розуміння необхідності жорсткого контролю за розвитком техніки. Спонтанний, непродуманий подальший iї розвиток і використання може поступово призвести до «постлюдського світу». Небезпека здійснення такого сценарію повинна породити необхідність більш пильної уваги, обговорення та аналізу вже існуючих проблем й розробки заходів, здатних забезпечити виживання людства в умовах сучасної техногенної цивілізації.

Ключові слова: техніка, наука, прогрес, людина, людство, техногенна цивілізація. 


\author{
S. A. YURIKOVA ${ }^{1 *}$ \\ $1^{1 *}$ Orel State Institute of Arts and Culture
}

\title{
THE PROSPECTS OF MANKIND IN CONDITIONS OF TECHNOGENIC CIVILIZATION
}

Objective. The outlines of the problems of the modern industrial society, reflection of its controversial nature and prospects of mankind in the environment. Statement of the problem: the rapid developments of science and technology gradually beginning at the 60 s lead to the realization of the problems that have been caused to understanding of a serious and careful monitoring of its development and the urgent philosophical analysis, such as risks by creating a future as "post-human" world. Scientific novelty. Is carried out a comprehensive approach to labeling and analysis of the problems faced by modern humanity in a technological civilization. The practical significance of the work lays primarily in the fact that the research needs a serious, thoughtful attention to these problems in the future in the aim to avoid dangers they pose to humanity. Materials presented in the article may be used in the teaching or social and humanities studies. Conclusions. The findings can be summarized in the following key positions: the scientific and technological progress is a major factor in the development of modern industrial civilization. It generated a large set of problems that require an understanding of the need for tight control in the technology development. Spontaneous, non-sustainable development and its use may gradually lead to a "post-human world". The danger of a scenario, needs to generate more attention, discussion and analysis of existing problems and developing measures will ensure the survival of humanity in the modern industrial society.

Keywords: engineering, science, progress, man, mankind, technological civilization.

\section{REFERENCES}

1. Bakhtin, M.M.. K filosofii postupka [Toward a Philosophy of the Act] // Philosophy and Sociology of Science and Technology. - M., 1985.

2. Bodriyar, Zh. Obshchestvo potrebleniya [Consumer society]. M., 2006.

3. Vizgin, V.P.. Kultura-znanie-nauka [Culture-Knowledge-Science] // Science and Culture. M., 1984.

4. Kutyrev, V.A. Problema vyzhivaniya cheloveka $v$ «postchelovecheskom» mire [Problem of Human Survival in the "Post-Human" Society]. M., 1989.

5. Popkova, N.V.. Filosofiya tekhnosfery [The Philosophy of Technosphere]. M., 2009.

6. Popkova, N.V. Antropologiya tekhniki. Problemy, podkhody, perspektivy [Anthropology of Technique. Problems, approaches, perspectives]. M., 2011.

7. Savkina, A.V. Kiberreligiya itekhnoyazychestvo v sovremennom obshchestve [Cyberreligion and Technopaganism in the Modern Society]. M., 2009.

8. Khaydegger, M. Vopros o tekhnike [The Question Concerning Technology]. M., 1993.

Надійшла до редколегії 10.05.2013

Прийнята до друку 10.09.2013 